\title{
Entre percursos, lugares e fronteiras do Amapá, rumo à terra prometida
}

\section{Silvia Carla Marques Costa ${ }^{1}$}

1 Doutoranda em Sociologia pela Universidade Federal do Ceará, Mestre em Cultura Visual pela Universidade Federal de Goiás. Professora efetiva no Curso de Licenciatura em Artes Visuais da Universidade Federal do Amapá, Brasil. E-mail: silvia3unifap@gmail.com

RESUM 0: A proposta deste texto é refletir o imaginário social e as crenças percebidas como representação do povoamento do Estado do Amapá. Ademais o texto chama atenção ao tratamento dado às políticas imigratórias na região de fronteira, Brasil e França. Trata-se de uma reflexão que sublinha o papel que essas políticas ocupam para contribuir com o melhoramento na qualidade de vida dos habitantes da fronteira. Este ponto geográfico, o Amapá, ainda pouco conhecido, constitui-se de um espaço hibrido em permanente processo de negociação das identidades. Compreender este espaço é revelar as negociações elaboradas nos interstícios dos processos culturais identitário. As relações de poder decorrente das experiências coletivas vão sendo dinamizadas nas fronteiras por meio de imaginário simbólico. A equação estabelecida tanto pelo atrativo econômico quanto pelo espirito de protagonismo social - numa terra em que tudo estar por fazer - é que mobiliza a esperança, o imaginário de sucesso, os desejos que reverberam a expectativa de ser o Amapá: "a terra prometida".

Palavras-chave: Fronteiras simbólicas e geográficas, Amazônia amapaense, imaginários e crenças.

\section{Between pathways, seats and borders of Amapá, toward the promised land}

ABSTRACT: The purpose of this text is to reflect the social imaginary and beliefs perceived as a representation of the State of Amapá settlement. M oreover the text calls attention to the treatment of immigration policies in the border region, Brazil and France. It is a reflection that underlines the role that these policies take to contribute to improving the quality of life of the inhabitants of the border. This geographical point, Amapá, still little known, consists of a hybrid space in permanent identities negotiation process. Understanding this space is to reveal the negotiations developed in the interstices of cultural identity processes. The relations of power stemming from the collective experiences will be streamlined border through symbolic imagery. The equation established by both the economic attractiveness as the social role of spirit - a land where everything is to be done - is that mobilizes hope, the success of imagination, desires that reverberate expecting to be Amapá, "the promised land" .

Keywords: symbolic and geographical borders, Amapá Amazon, imaginary and beliefs.

\section{INTRODUÇÃO}

Poder morar ...poder sair

Poder chegar ...poder viver .....e depois de partir poder voltar E dizer: este aqui é o meu lugar

A Terra Prometida Vinicius de Moraes 
O trecho acima - parte da composição de uma música serve como epígrafe neste artigo, que discorre sobre imaginários e crenças que reforçam a representação social da consolidação do povoamento do Estado do Amapá/AP ${ }^{1}$. Compreendemos como imaginários, a produção de sentidos no que se refere aos modos de ver e ser visto. Pois é sob o fundo das expectativas criadas e vínculos idealizados que torna visível a ocupação dessa região norte do Brasil, a qual denominamos de "terra prometida"lugar de aceno de uma nova vida - como bem expressa à letra da música, espaço de esperança, de felicidade e de pertencimento.

O deslocamento em massa para esta região nas últimas décadas do século passado, principalmente para a capital Macapá/AP, foi estimulado por um conjunto de representações sobre o lugar. Contudo, uma parcela significativa de imigrantes se movimentam no então vazio geográfico do então território transfronteiriço de integração física entre Brasil-Amapá e Guiana Francesa.

$\mathrm{Na}$ virada do século XXI as políticas de fronteiras incorporam novos significados que reconfiguram as relações de poder. A metamorfose fronteiriça, consolidada pela construção da ponte binacional em 2011, abriu um rol de oportunidades de cooperação entre mercados econômicos, cultural e político. Um cenário de cooperação entre Brasil e França, vem sendo desenhado por uma relação de aproximação em várias instâncias, imprimindo novos usos políticos do território franco-brasileiro à medida que, diversas políticas territoriais vão sendo implementadas.

Propostas de cooperação são institucionalizadas e articulam processos híbridos projetando ações culturais, tanto nas referências do estado do Amapá/AP quanto no departamento da Guiana Francesa². Tais processos têm em perspectiva o desenvolvimento social em várias áreas, entre algumas estão: segurança, saúde, transportes, agricultura, língua, educação etc... Embora estas políticas de atendimento ao social venham se constituindo em agenda permanente de Brasil e França, ainda não se efetivaram num avanço de qualidade de vida para os habitantes da fronteira.

Este ponto geográfico, o Amapá/AP, ainda pouco conhecido para alguns, constituise de um espaço hibrido em permanente processo de negociação. A cada projeto e-

\footnotetext{
${ }^{1} 0$ Amapá é uma das 27 unidades federativas do Brasil. Está situado a nordeste da Região Norte, no escudo das Guianas. 0 seu território é de 142.828,521 km², sendo delimitado pelo estado do Pará a oeste e sul, pela Guiana Francesa a norte, o Oceano Atlântico a leste e o Suriname a noroeste.

O município de Macapá é a capital e maior cidade do estado, sendo sede da Região M etropolitana de Macapá, a única no estado. Ao todo o estado tem 734995 habitantes, distribuídos em seus 16 municípios. A capital concentra 437256 habitantes, ou seja, quase $60 \%$ da população amapaense. 0 Amapá é um dos mais novos estados do país, sendo também o segundo estado brasileiro que mais possui áreas protegidas em seu território. Dos 14,3 milhões de hectares que 0 estado possui, $72 \%$ são destinados a unidades de conservação e terras indígenas (10,5 milhões de hectares). O estado abriga o maior parque nacional do país (M ontanhas do Tumucumaque) e um dos maiores do mundo com quase 3,9 milhões de hectares.

2 Em recente reportagem do canal de telecomunicação a emissora Globo no programa Fantástico 28/09/2014 mostrou a relação tensa que existe entre a fronteira do Brasil na cidade do Oiapoque e o lado da cidade guianense Saint George e travessias de brasileiros na zona de fronteira para o trabalho clandestino de garimpeiros entre estes espaços. http://gl.globo.com/fantastico/noticia/2014/09/fantastico-revela-vida-degarimpeiros-ilegais-na-guiana-francesa.html
} 
laborado, politicas públicas institucionalizadas e ações educativas - em sua forma ampliada - merecem ser discutidas com mais precisão e visibilidade. Essa demanda reflexiva que este artigo se propõe é um mergulho nas águas escuras dos rios que cortam a Amazônia em territórios de fronteiras porosas e a complexidade cultural das cidades localizadas em zonas de fronteira. Compreender este espaço é revelar as negociações elaboradas nos interstícios dos processos culturais identitários que a experiência do vivido vai sendo dinamizada nas fronteiras geográficas e simbólicas. Pensar o simbólico é pensar um poder de construção da realidade que tende a estabelecer uma ordem gnoseológica: o sentido imediato do mundo - e em particular, do mundo social - (BOURDIEU 20002, p. 09).

A partir desse vaivém analítico das concepções de fronteiras, propomos no primeiro momento tecer uma compreensão esgarçada de como os imaginários sobre o espaço da Amazônia, serviram de motes para ocupar a região e o poder simbólico que vai se tecendo envolto de imaginários. Na dinâmica desse movimento, refletimos no segundo ponto sobre quais os trânsitos de negociações entre os sujeitos sociais, seus imaginários e a negociação no encontro com a cultura amazonida, revelando outras identidades de quem chega para morar, de quem pode chegar e de quem depois de partir pode voltar.

Com base nessas percepções de imaginários e identidades negociadas nos espaços de diversidades culturais, acionamos para a reflexão conceitos de Homi Bhabha (2005) e Stuart Hall (2006) entre outros autores, para compreender processos de sociabilidades, trocas culturais e aprendizados como possibilidades de hibridização que percorrem as dinâmicas culturais institucionalizadas, territoriais e simbólicas em zonas de fronteira, especificamente na Região Amazônica. Ou seja, as reflexões perpassam pela atenção aos links que os sujeitos se constituem e se constroem.

Essas construções estão fundamentadas em narrativas fantasiosas de lendas e manchetes televisivas, que descrevem o Amapá/AP como espaço inóspito, povoado por animais exóticos e com rara presença humana. Tais imaginários geram expectativas de ser esta uma terra de eldorado, de oportunidades, prosperidades, felicidade, de esperança de uma vida melhor e de nela produzir o progresso. É nesse viés que as considerações finais, sem expectativas de finitude, se configuram e se insinuam como proposição de entendimentos das subjetividades dos sujeitos nas interações socioculturais, situação peculiar nas zonas de fronteiras.

\section{OCUPAI A TERRA!}

Não é novidade alguma que os atrativos para povoar a região norte do Brasil sempre estiveram nas agendas e conjunturas do Estado Nação, como forma de expansão territorial compreendido na forma do mundo ocidental civilizado. A ideia de ocupa- 
ção da bacia amazônica ${ }^{3}$, orquestrada pela racionalidade do estado e empresas multinacionais ${ }^{4}$, traz a reboque ideias transplantadas, idealizadas de fundir a riqueza local inexplorada, virgem, com a gana do progresso e da tecnologia de ponta do modus operandi da civilização do homem europeu e estadunidense. Tais prerrogativas foram versadas por determinadas formas de ser e compreender a dinâmica da vida social. Embora os argumentos fossem balizados pelo tom 'apaziguador' de contribuição e desenvolvimento para aquele espaço geográfico o que temos visto são processos de exclusão e estereótipos das percepções sobre as ações culturais dos povos da flores$t^{5}$.

Cabe destacar que as investidas tanto estatais quanto empresariais foram forjadas na perspectiva de progresso e civilidade, seus argumentos fundantes fortalecem e impactam certos tipos de imaginários da região norte até os dias atuais. Argumentos que intensificados e atrelados ao apelo econômico, quanto pelo espírito de protagonismo social - numa terra em que tudo estar por fazer, foram e são recorrentes quando o assunto é ocupar estados da região norte, neste caso o Estado do Amapá. Assim se plasmou os imaginários da terra prometida: de que em se plantando tudo dá. Estes imaginários atrelados à eficácia simbólica foram responsáveis pela propagação de três ondas migratórias no estado do Amapá .

Embora a "desconfiança obstinada ao imaginário" (GIRARDET, 1987, p. 09), seja ainda uma conversa delicada para as ciências sociais, não podemos ignorar que tal dimensão esteve e atualmente nos interpela frequentemente nos processos de interação cultural. Neste enfoque Bourdieu (2002) considera que é na prática social que critérios de identidades são construídos e:

(...) são objetos de representação mentais, quer dizer, atos de percepção e apreciação, de conhecimento e reconhecimento em que os agentes investem os seus interesses os seus interes-

\footnotetext{
${ }^{3}$ A bacia Amazônica é uma região de 5,5 milhões de $\mathrm{KM}^{2}$ de extensão dos quais 3,6 localizam-se em terras brasileiras. Sua superfície cobre $1 / 3$ da América do Sul e ela constitui o maior sistema hidrográfico do mundo. (CARRASCO, 1987, p. 79).

${ }^{4}$ Manuel Arruda revela um panorama dos discursos para a ocupação da Amazônia via processo de internacionalização do capital bem como a consolidação do capital estrangeiro desse o fim da II Guerra M undial,. Despontando no Governo de Getúlio Vargas de 1930/45 e 1950/54. (Arruda, 1979, 39). Onde foi construída uma cidade Por Henry Ford no meio da floresta, como também é o caso da ICOMI no estado do Amapá , que explorou seu minério por 50 anos deixando problemas socioambientais gravíssimos e ainda a abertura da Zona Franca de Manaus em 1956 que o autor assinala como a invasão estrangeira da Amazônia. A companhia Jari Florestal ocupa " 3,7 milhões de acres de terra (metade da Holanda), ao longo dos rios Jari e Peru, no território Federal de Amapá" . (p. 43) no ano de 1967 a 1980.

${ }^{5}$ Caboclos, ribeirinhos, indígenas.

${ }^{6}$ A primeira onda migratória no Amapá, data do período colonial e se insere no processo de ocupação e controle sobre as terras amazônicas e foi orientada pela necessidade de defesa do território das invasões estrangeiras. A segunda onda migratória registrada na história amapaense, data da Era Janary - quando da separação dessas terras do Estado do Grão Pará e Maranhão e criação do Território Federal do Amapá. A terceira onda migratória emerge na década de 1990, com a implantação da chamada Área de Livre Comércio de Macapá e Santana.
} 
ses e os seus pressupostos, e de representações objetais, em coisas (emblemas, bandeiras, insígnias, etc.) ou em atos, estratégias interessadas de manipulação simbólica que tem em vista de terminar a representação mental que os outros podem ter dessas propriedades e dos seus portadores. (p. 112)

Para Barreira (1996) intercedendo à discussão das recentes investidas do imaginário na dimensão politica nos adverte que o processo analítico entre a imagem e 0 simbólico enfatiza que "A representação simbólica, não seria assim, apresentação pura e simples do que ela significa, tendo por este motivo um sentido sempre abstrato". (p. 30). Consideramos, portanto que a reflexão dos autores está imersa nos posicionamentos reflexivos da história das ideias e do pensamento proporcionando 0 alargamento e entendimentos acerca das relações de sociabilidade, dos trânsitos entre fronteiras geográficas e das relações socioculturais simbólicas. Implica novas configurações provocaram processos irreversíveis pelo contato com outros povos e outras culturas e que tais configurações perpassam pela sedução e composição do mito e do imaginário.

A dimensão do Imaginário, portanto qualifica, aciona e mobiliza racionalidades transcorridas por uma animação criadora no qual o mito é um "conjunto ligado de imagens motrizes" e que tem "apelo ao movimento, incitação à ação e aparece em definitivo como um estimulador de energia de excepcional potência". (SOREL apud GIRARDET, op cit, p. 13). Justifica-se que 0 imaginário, circunstanciado e dinamizado pelo alcance do mito, plasmam discursos levando a crer percepções auspiciosas e ao mesmo tempo ambivalentes.

Os imaginários sobre a região da Amazônia e sobre o estado do Amapá/AP contém construções de uma 'realidade' que se referem a uma terra em que precisa de pessoas com visão profissional de progresso e tecnologia, garantidos por uma lógica de civilidade em detrimento ao 'primitivismo' encontrado em terras distantes, desprovida de meio de sobrevivência e, que quem, dispor estar nesta terra trará benefícios contrários aos modos dos selvagens. Compreendemos que esta percepção varreu da esfera reflexiva a versão cultural dos povos da floresta, subjugando ou colocando em seu lugar, outros modos de entender a lógica 'nativa' de relacionar e viver em meio à floresta.

Estes argumentos são parte do imaginário sobre a ocupação das terras do Amapá/AP e, é o cenário de sedução que vêm sendo fortalecido, fazendo com que se aliem na produção de sensação e sentimentos sobre o lugar. A promessa de alcance de sucesso e de encontrar neste espaço satisfação para a vida é que os imaginários se transformam em desejos, crença que faz para muitos, ser o Amapá/AP: "a terra prometida". Neste caso podemos considerar que os argumentos que fizeram com que a necessidade de ocupar a Amazônia e não diferente o estado do Amapá/AP, revelassem imaginários que destituíssem e, ao mesmo tempo recolocassem percepções não 
unilaterais, mas hibridizadas e negociadas de quem aqui está e de quem vem ficar. Bourdieu (2002) entende que a dimensão entre imaginário e simbólico se reveste pela capacidade quase mágica das palavras e "resulta do efeito de objetivação e a oficialização de facto de que a nomeação publica realiza à vista de todos, de subtrair ao impensado e até mesmo ao impensável a particularidade que está na origem do particularismo (...)" (p. 117).

0 imaginário presente em particularidades de cada região e povos sempre existentes tem agora uma preocupação vertebral para as interações e sociabilidades sociais, pois o imaginário evoca poderes, modos de perceber e de se constituir percepções que podem ser deflagradoras como fronteiras simbólicas e que "é necessário saber descobri-lo onde ele se deixa ver menos, onde ele é completamente ignorado (...)", (BOURDIEU, 2002, p.7). 0 autor acrescenta que com "efeito, esse poder invisível 0 qual só pode ser exercido com a cumplicidade daqueles que não querem saber que Ihe são sujeitos ou mesmo que o exercem (p.8)" pode ser um entre tantas peculiaridades envolvidas no imaginário e o poder simbólico.

Há certamente nesta relação algo que tentamos visualizar e compreender o deslocamento em massa para o Estado do Amapá/AP nas últimas décadas ${ }^{7}$ levando em conta esferas que precisam ser discutidas com mais profundidade e que estão atreladas diretamente as questões de identidades.

Não podemos ignorar que imaginários e o simbólico cercam eficazmente a sedução às terras da Amazônia, além de servirem de atrativos, quase sempre foram/são marcados por estereótipos que se vinculam a falta de progresso e de civilidade. Porém é emergente discutir estas relações sem que os argumentos possam encontrar posicionamentos entre opressores e vitimas. A partir desse ponto de vista estabelecemos que o enfoque dado pela sedução dos imaginários é de que deflagram subjetividades nos sujeitos, e que "o mundo social é também representação e vontade, e existir socialmente é também ser percebido como distinto. (BOURDIEU, 2002, p. 118)". Assim é no encontro dos sujeitos sociais, suas interações e sociabilidade múltiplas que as questões atreladas ao imaginário, pertencimento e lugar que identidades se ressignificam e, hibridizados, possibilitam a reinvenção de si e das relações geográficas e simbólicas que se intensificam e se singularizam nestes processos desfronteirizados.

Desse modo consideramos que os estudos revelados pela compreensão da critica pós-colonial ${ }^{8}$ ampliará e desmistificará os encontros culturais e que desde sempre

\footnotetext{
${ }^{7}$ A população do Estado do Amapá em 2010 era de 669.526. Em 2014 está estimada em 750.912. Fonte IBGE

${ }^{8}$ Segundo a avaliação de Sérgio Costa, os estudos pós-coloniais "não constituem propriamente uma matriz teórica única." Trata-se, segundo o autor, "de uma variedade de contribuições com orientações distintas, mas que apresentam como característica comum esforço de esboçar, pelo método da desconstrução dos essencialismos, uma referência epistemológica crítica às concepções dominantes da modernidade." A crítica póscolonial, "iniciada por aqueles autores qualificados como intelectuais da diáspora negra ou migratória - fundamentalmente imigrantes oriundos de países pobres que vivem na Europa Ocidental e na América do Norte - teve, na crítica literária, sobretudo na Inglaterra e nos EUA, a partir dos anos 1980, suas áreas pioneiras de difusão" (COSTA, 2006, p. 84).
} 
foram se articulando em possibilidades da existência e se refazendo em partilhas e não apenas em referenciais de ficções ${ }^{9}$.

Acreditamos que as perspectivas dos estudos culturais são potenciais teóricos e metodológicos que referenciam a discussão sobre imaginários e identidades nos processos de trocas culturais. É rearticular posicionamentos teóricos para compreender como os trânsitos de ocupação de terras, sejam elas geográficas e simbólicas, estão ocorrendo na atual Amazônia.

\section{INÍCIO E NUNCA UM FIM DE REFLEXÃO}

A contribuição do imaginário como meio fascinante, seduziu e seduz muitos sujeitos às terras da Amazônia e, oportunamente concretizou-se a ocupação do estado do Amapá/AP. Vinculadas a ideia de uma terra em que "tudo está por fazer", a projeção se consolida em processos de "deslocamento", enredados pela descentração dos indivíduos tanto de seu lugar no mundo social e cultural quanto de si mesmos. Esse impulso de sair de um lugar e ir para outro, não pode ser compreendido como traslados de invasores de terras alheias, conquistadores, forasteiros, exploradores ou simples sujeitos que buscam desesperados um lugar ao sol.

Neste contexto quem chega e, quem já se encontra na fronteira geográfica e simbólica devem levar em conta novos modos de relacionar-se e entender os trânsitos físicos na era globaliza. As fronteiras geográficas antes severamente demarcadas e instituídas, hoje se apresentam fluidas e impactam substantivamente as relações e identificações dos sujeitos quando povos e cultura se encontram. Hoje o acesso e a facilidade de locomoção intensificada pelos serviços globalizados possibilitam que estas fronteiras se aproximem ou se diluam. Quanto à dimensão do simbólico "é preciso, pois romper com o economicismo - marxista ou qualquer outro - que reduz 0 regionalismo à paixão, ou mesmo a patologia (...)" (BOURDIEU, 2002, p. 145).

As aproximações fronteiriças entre o Brasil e o Amapá/AP marcou a urbanização de várias áreas, municípios do estado, estas marcas foram (re)desenhadas na dinâmica negociada das relações e interações culturais e, sobretudo na produção de identidades e, também de percepções de pertencimento em relação ao lugar. Como observa 0 crítico cultural Stuart Hall, a identidade ${ }^{10}$ deve ser entendida como "móvel", formada e transformada continuamente em relação às formas pelas quais somos representados ou interpelados nos sistemas culturais que nos rodeiam (HALL, 2006). Concordamos com o autor no entendimento de que as identidades são processos de identificações que vão sendo redefinidos na trajetória histórica e cultural dos sujeitos

\footnotetext{
${ }^{9}$ Os estudos que versam sobre as explorações urdidas na ficção literárias e artísticas sobre o Brasil e também sobre a Amazônia têm aportes na concepção de idealismos compondo uma imagem original e singular sobre o lugar. M aria Angela D'Incao e Isolda M aciel da Silveira - Amazônia e a Crise da M odernidade - 1994.

${ }^{10}$ Nesse sentido, ao criticarem os essencialismos problematizam a questão e ou o conceito da identidade e afirmam que a identidade é formada ao longo do tempo da constituição dos sujeitos culturais e por isso pensam em processo de identificação e não em identidade fixa.
} 
e, não biologicamente. Ou seja, os sujeitos assumem identidades diferentes em diferentes momentos.

Nesse horizonte em que as identidades se movimentam e se constroem, observamos que os impactos exercidos pela sedução dos imaginários sobre o Amapá/AP e 0 contato com os sujeitos de tantas outras culturas, não se pode dizer que as formas de ver e perceber o lugar amazônico e, sobretudo vivenciar este espaço no cotidiano, possam as identidades ter permanecido fixas e imutáveis. As implicações desse encontro de várias culturas nos fornece uma pista analítica, levando em conta a mundialização da cultura que se revela através dos crescentes processos migratórios, pela ruptura dos marcos espaciais necessários para o aumento da extensão geográfica das atividades econômicas, na mudança de hábitos, comportamentos e valores.

Uma cultura mundializada não implica 0 aniquilamento das outras manifestações culturais, ela coabita e se alimenta delas (ORTIZ, 2000). Não aniquila no sentido de reverenciar, preservar, mas, a partir de uma visão colonialista, de transformá-la em bem de consumo com vistas ao lucro.

Contrária a este lógica, entendemos que o processo desfronteirizado entre as percepções e as identidades negociadas é um modo de insurgência politica cotidiana e, na dimensão pós-colonial, culturas diferentes além de conversar entre si, se hibridam e se traduzem em singularidades localizadas sem que uma se sobreponha a outra.

Acreditamos que este processo pode ser discutido na perspectiva dos encontros com terras da Amazônia e do Amapá/AP - sem, contudo negligenciar os momentos que ainda existem de opressão, monopólio e escândalos econômicos - vividos pelos sujeitos. 0 que temos em probabilidades é de que atualmente o discurso sobre fronteiras, com ênfase nos argumentos da cultura e da produção de sentidos revestidas pelas reflexões de Identidades plurais seja contrário à ideia que podem vir a ser "engolidas" por uma cultura receptora, e "digerida" de forma tal a se adaptar a todo universo simbólico de uma coletividade. A reflexão é de que não se agregue posicionamentos de essencialização das identidades, que foram consolidadas pelas concepções dominantes de modernidade ${ }^{11}$.

Neste enfoque em que as fronteiras geográficas foram sendo borradas com os trânsitos entre pessoas para várias terras do globo, não há como negar que um tipo diferente de mudança estrutural transformou as sociedades modernas no sec. XX. Esta premissa é sublinhada com reflexões acerca das identidades que possam ser deflagradas para além dos aportes teóricos da teoria critica clássica, atinente e disposto na ação de reflexividade, contrariando discursos unilaterais que, por vezes, ausentes de uma vigilância dos modos de como foram construídos e constituídos nossos modos de pensar, fortalecem grandes narrativas e seus preceitos hierarquizantes. (BHA$\mathrm{BHA}, 2005)$

${ }^{11}$ A significação mais ampla da condição pós-moderna reside na consciência de que os "limites" epistemológicos daquelas ideias etnocêntricas são também fronteiras enunciativas de uma gama de outras vozes e outras histórias dissonantes, até dissidentes. (BHABHA, 1998: 23-24)

PRACS: Revista Eletrônica de Humanidades do Curso de Ciências Sociais da UNIFAP 
Para tanto os argumentos contidos na linha reflexiva dos estudos culturais revestidos em modos de resistência política a ação científica tem expectativas para fazer uma imersão nas 'culturas por vezes negadas' ou por posicionamentos pouco visíveis como e o caso com dispositivos de imagens e arte que produzem e impactam substancialmente modos de ver e de agir no espaço e tempo. De modo que tais posicionamentos reflexivos se aliam a novas percepções acerca dos saberes que vem sendo articuladas pela dimensão visual atinente aos propósitos de visibilidades as versões de uma história excluída e as vozes que por alguns anos foram silenciadas das discussões sociais e acadêmicas ${ }^{12}$.

É com este propósito, portanto que entendemos que discutir as questões de territorializações em via a processos hibridizados no espaço da Amazônia é compreender que interstícios desse movimento são contingenciais que perpassa pela construção e produção de imagens, imaginários e representações do lugar vivido. A ideia de contingência é um aspecto interessante para se perceber produções de sentido sem, contudo abrigar nas explicações critica a percepção de teorias totalizantes e universalistas. Para tanto sugere um afastamento do conceito de cultura como totalidade de conteúdos canônicos e propõe a visão de cultura como "uma produção desigual e incompleta de significação e valores, muitas resultantes de demandas e práticas incomensuráveis, produzidas no ato de sobrevivência social (BHABHA,1998 p. 241).

0 autor sugere pensar a cultura como "lugar enunciativo" que seria um processo mais dialógico e liberal, com possibilidades de abarcar os deslocamentos e realinhamentos, resultados de articulações culturais e do hibridismo cultural alternativo. Da articulação do presente enunciativo com a cultura resultaria a transformação do "outro objetificado" em "sujeitos de sua história e experiência." (BHABHA, 1998, p. 248). Geertz (2012) é enfático ao posicionar-se que os sentidos construídos são dispostos na dimensão cultural como 'estrutura de significado através das quais os homens dão forma a sua experiência' (p. 135).

Para Hall (2006), Bhabha (2005) os estreitos contatos resultantes de relações com povos e culturas, onde as trocas e os processos de sociabilidade foram próximos e intensos, não se pode mais entender estas aproximações apenas saudáveis para um lado e altamente desfavoráveis para o outro. 0 que devemos ter em expectativa desses encontros são trocas e, diria aprendizados não mais por polarizações e entendimentos binários sobre a vida em sociedade.

Para Bhabha (2005) este processo configura-se nos estudos pós-coloniais que "nenhuma cultura é jamais unitária em si mesma, nem simplesmente dualista na relação do EU com o Outro". ( $p, 65)$. É este vestígio de demanda transformadora, entremeada por uma crise de paradigmas e percepções sobre o que resultou, ou talvez o que

12 Esta discussão vem sendo ampliada nas reflexões na TESE de doutorado no Programa Interinstitucional em Sociologia entre a Universidade Federal do Ceará-UFC e a Universidade Federal do Amapá - UNIFAP/DINTER da autora do texto. Assim a autora considera que a produção de sentidos, especialmente urdidos na experiência com o lugar e as sensorialidades do vivido agregam posicionamentos, percepções e projeções críticas de como viver em meio e imerso na Amazônia. 
se produz e, produziu dessa dinâmica de trocas impetradas pela globalização. Assim os estudos que vislumbramos para os processos de ocupação do estado do Amapá/AP vêm reivindicar novos posicionamentos sobre as reflexões que envolvem 0 sujeito ou nas palavras de Bhabha, (idem) em posicionar-se em fronteiras e "situar nas margens deslizantes do deslocamento cultural" $(p, 46)$

Neste sentido não podemos considerar a condição binária do encontro e trocas dos saberes culturais como transplantados, alienantes ou abolidos. Insistir neste posicionamento é aceitar e acreditar que a ideologia do Outro como primitivo em detrimento aos civilizados permanecem. Todavia contradizendo estas prescrições por vezes, tão bem 'intencionadas' não podemos acreditar que a cultura e os saberes do Outro foram simplesmente extintos. A crença tanto de Hall (2006) quanto de Bhabha (2005) é de que as formas de trocas são híbridas dinamizadas como projeção politica entre os sujeitos e suas negociações intersubjetivas.

A proposição destacada por tais estudos não é, só contradizer aos imaginários hegemônicos e as metanarrativas, mas compreender que dentro dessas trocas, desses contatos, muitas vezes violentos fisicamente - como é o caso da escravidão - não há apenas vencedores, nem sequer automatizar os perdedores, há relações de aprendizados e de sentidos produzidos no encontro dessas vivencias.

0 pós-colonialismo surgiu como um modo de pôr em questão as velhas dicotomias que legitimaram a supremacia do eu nacional imperial. Como sugere Stuart Hall, o termo pós-colonial não se restringe a descrever uma determinada sociedade ou época, mas reler a colonização como "parte de um processo global essencialmente transnacional e transcultural, produzindo uma reescrita descentrada, diaspórica e mesmo global das grandes narrativas imperiais do passado, centradas na nação". (HALL, 2006, p. 109). Seu valor teórico, ainda nas suas palavras, recai sobre sua recusa de uma perspectiva do "aqui e lá, de um então e agora, de um em casa e no estrangeiro" (HALL, 2006, p. 109).

\section{PENSAR 0 GLOBAL NA REFLEXÃO DE IDENTIDADES AMAZONIDAS}

0 processo de globalização trouxe consigo aspectos e combinações de relações sociais muito nítidas, a investida foi uma combinação que levou a cabo ideias de hierarquização de saberes, legitimação de determinada 'cultura', autorização de certas concepções sobre os indivíduos e sobre o mundo. Combinadas estas ideias determinou única versão de narrativa sobre a sociedade, como extraordinária e autentica forma de perceber o mundo social. Desse processo foram forjados argumentos que justificavam e impediam outras maneiras de mediar o olhar sobre o mundo.

A ideia de nação, territorializada e fronteirizada foi talvez, no nosso entendimento, uma das grandes invenções que proporcionaram e consolidaram o imaginário sobre sociedade e a posição do sujeito. Este imaginário fez com que outras culturas vissem suas organizações sociais como primitivas e posicionando os povos como inferiores e 
passíveis de orientação intelectual, sentimental e social.

Hall (2006) e Bhabha (2005) entendem que o processo de globalização promoveu trocas que articularam e intercambiaram signos culturais. Porém anteriormente distinguidos e, percebidos, como processos que se pronunciavam pela tensão e conflito permanente e anulavam qualquer processo de aprendizado, esvaziando por fim a diversidade cultural existente. Ambos apontando outras relações de entendimentos desse encontro cultural entre os povos: Argumentam que estes processos se dão na forma de negociação subjetiva de tradução, nomeada por Bhabha como terceiro espaço.

Nesta direção os autores estabelecem novos parâmetros e argumentos que circunscritos em compreensões mais distendidas ou de fluxos descontínuos e contraditórios que envolvem processos de ação e sociabilização entre os sujeitos em espaços e lugares de fronteiras. Esta perspectiva é mais que uma proposta, é um convite de reaprender e perceber que há outros atravessamentos perceptivos, outros pontos de vista e, outras relações que façam não só negar hierarquizações de saberes e fazeres culturais, mas trazer á tona aprendizados que foram negligenciados pela ideia binária das metanarrativas envolvidas pelo encontro com o Outro/diferente e as trocas culturais.

Neste sentido os Estudos Culturais vem deslocar o ponto de reflexão sobre como as relações sociais foram construídas ao longo do processo de globalização, onde 0 marco se deu nos processos de colonização e de marginalização de culturas diversas e adversas aos preceitos cristalizadores do modernismo construído pela ideia etnocêntrica.

Assim entendemos as discussões dos autores como 'otimistas', não apenas por requerer adicionar as culturas silenciadas no circuito intelectual com tolerância e aceitação em nome de um respeito moralizador, mas tratá-los ou vê-los como protagonistas da existência possível, organizadas e singularizadas em biografias individuais e coletivas. 0 conceito de terceiro espaço, lugar de negociação e de tradução de culturas, circunstanciados pelos processos de aprendizados.

Com isso a nossa compreensão sobre a vida no Amapá e seus encontros culturais são momentos de hibridação em plena negociação no terceiro espaço e não aquele que alguém sobrepõe ao saber do outro, mas de surgimento de um terceiro elemento que surgi como aprendizado entre os sujeitos. Ou seja, processos de tradução entre saberes culturais que vão sendo negociadas experiências intersubjetivas e coletivas. Comungamos da ideia de que esta nova compreensão, além de não evocar ganhadores ou perdedores, dão visibilidades aos sujeitos em suas singularidades.

As noções de terceiro espaço, hibridações e negociações são conceitos sinequanon deflagradores da teoria pós-estruturalista e pós-colonial para se discutir os processos contemporâneos de construção identitárias dos povos que foram escravizados e subalternizados, sobretudo as relações e sentimentos de viver e se posicionar nas margens das fronteiras. 
Observa-se a partir dessa perspectiva que o processo de trocas e contatos são possíveis mecanismos de protagonismo e de visibilidade vivenciados pelos sujeitos. Nas palavras de Bhabha este processo é uma "transgressão é um ato criativo gerado pela insurgência de tradução cultural" (p. 44). Desse modo para Bhabha olhar os processos de tradução e negociações como elaborações contínuas, e que devem levar em conta o tempo e a disponibilidades dos indivíduos é uma forma de não ser rebaixado em suas tradições e desqualificar seus aprendizados. Desse modo a população e os espaços do estado em suas zonas de fronteiras são instantes de permutas que localizam outras formas de entender e viver na floresta.

Bhabha (IDEM) nos diz que atualmente construir uma ideia de que estamos no mesmo grupo não é mais possível, pois os interesses são particularizados e vividos diversamente. Neste sentido à identificação sobre determinadas situações ou momentos da vida no cotidiano é condição dos sujeitos na contemporaneidade, circunstanciados ele é situado, tem interesses particulares e muitas vezes são conflituosas e contraditórias.

\section{PARTICULARIDADES - "AQUI COMEÇA O BRASIL" E "ALI COMEÇA A EUROPA"- EN- TRE FRONTEIRAS}

"Aqui começa o Brasil" e "Ali começa a Europa" - mote símbolos das cidades do Oiapoque-Brasil e Saint George-Guiana Francesa respectivamente essas cidades balizam a fronteira entre os dois países, comportando uma ampla gama de significados culturais, políticos e econômicos.

A construção da ponte binacional entre Brasil e Guiana Francesa derivou de um contexto econômico cada vez mais mundializado, no qual o intercâmbio, tanto econômico quanto cultural, exigiu a implantação de infraestruturas como rodovias, áreas de telecomunicações e informática, sendo estes serviços indispensáveis e capazes de conectar territórios e criarem possibilidades de cooperação e interações socioespaciais.

A materialização dos espaços produzidos pela fronteira possibilitou novas dinâmicas para ambos os territórios. O lado Francês é muito cobiçado por brasileiros, nas últimas décadas, tem recebido imigrantes ilegais de origem brasileira que buscam oportunidades de trabalho e melhorias nos padrões de vida. A ilegalidade submete esses trabalhadores a ofícios degradantes, principalmente, na área da construção civil, vivendo, não raro, em condições precárias e exaustivas jornadas de trabalho. Há ainda a existência de atividades ilícitas como os garimpos brasileiros em território Frances, além do trafico de armas e drogas. Do lado brasileiro a qualidade de infraestrutura é muito inferior à francesa, porém o atrativo se da pela possibilidade de diversão ligada a prostituição juvenil, mulheres, a boa aceitação da moeda euro, tráfico de mercadorias, da possibilidade de comerciantes franceses se estabelecerem na região sem nenhuma fiscalização, considerando que o euro que lá investem está pre- 
sente no imaginário de enriquecimento de outros comerciantes.

Apesar dos muitos interesses pelos quais estão ligados brasileiros e franceses na fronteira do extremo norte brasileiro, as disparidades culturais e econômicas são perceptíveis. Superti (2011) tem indicado que as condições de precariedade entre a fronteira Brasil/Oiapoque e França/Saint-Georges possui entraves estruturais para a convivência das duas cidades, duas nações, para a autora:

Mesmo nessas condições, ambos os municípios têm importância na integração do estado com os mercados interno e externo. Pois, promovem a ocupação da fronteira e são responsáveis pela manutenção ordinária das relações econômicas e sociais que vivificam e garantem a soberania nacional na área lindeira, cumprindo, portanto, um papel na segurança e defesa da fronteira amazônica nacional. (SUPERTI, 2011, p. 11)

A ligação entre essas Comunas apresentam problemas de varias ordens, suas assimetrias e contradições se desdobram em um problema comum nas fronteiras: a propagação de estereótipos, alimentados principalmente por parte dos franceses, que por se apresentarem numa condição de superioridade , acabam por transformar a parceria numa relação ainda mais difícil.

A maneira como o governo francês controla a entrada e saída de pessoas em seu território é bem diferente do que ocorre do lado brasileiro. Enquanto o lado pobre demanda pela presença de franceses com interesse de usufruir de seus euros, a outra margem vive 0 avesso por ter que conviver com a presença incomoda de brasileiros diariamente em Saint-George. Por esse motivo, atos xenofóbicos não são raros por parte da polícia francesa e pela própria população local. São noticias nos jornais locais as agressões contra brasileiros ilegais e a expulsão de até mesmos os que se aventuram em um passeio corriqueiro de conhecer a terra europeia.

A imagem estereotipada do migrante tem sua formação já na era colonial. 0 modo como os estereótipos produziram a construção do outro no pensamento colonial é ponderado nas reflexões de Bhabha (2005). Segundo o teórico, a construção do outro colonial se apóia na articulação de sujeitos diversos e distintos pela condição racial e sexual, por meio de discursos construídos com o propósito de eliminar o outro. Para Bhabha, o estereótipo é um mecanismo engenhoso de caracterizar o outro como invariável e previsível. 0 estereótipo é também um modo ambivalente de construir 0 outro ${ }^{13}$ :

O estereótipo (...) no discurso colonial, tanto para o colonizador como para o colonizado, é a cena de uma fantasia e defesa semelhantes - o desejo de uma originalidade que é de novo ameaçada pelas diferenças de raça, cor e cultura. (...) - uma mímica grotesca ou uma "duplicação" que ameaça dividir

${ }^{13}$ Ambivalência é um dos termos mais frequentes na obra crítica de Homi Bhabha, tomado originalmente da teoria psicanalítica de Freud. Bhabha sustenta que o discurso colonial é ambivalente porque o outro, o nativo, é ao mesmo tempo objeto de desprezo e de desejo. 
a alma e a pele não diferenciada, completa, do ego (BHABHA, 2005, p.117).

Para o autor, isso concebe a atitude do sujeito colonial, que no propósito deste estudo identificamos como representado pela cultura francesa dominante em relação ao outro - no caso, o brasileiro. Então a imagem do brasileiro nessa relação fronteiriça é construída com base nas características culturais, étnicas ou raciais compreendidas como símbolos de inferioridade; então todos os indivíduos identificados com este grupo são tratados de forma semelhante, com exceção daqueles que possuem atributos que lhes permitam "provar" que são exemplares distintos do conjunto. È o caso de alguns brasileiros que migraram e conseguiram se estabelecer em solo Guianense, na maioria através do casamento.

Nesse sentido, o lado brasileiro, representado pela cidade do Oiapoque é, portanto, espaço transnacional no interior da Guiana Francesa, mas está fadado à periferia do sistema de integração, o que evidencia a existência de fronteiras simbólicas no cerne da fronteira. Como os encontros culturais são inevitáveis, nesse contexto, é certo que os conflitos aflorem. Contudo, há um esforço que insinua certa habilidade de negociação entre esses sujeitos e um conhecimento cultural de ambas as culturas, o que confere a capacidade de negociar suas identidades e 0 espaço que os circundam nesse "entre- lugar".

\section{CONSIDERAÇÕES SEM FINAL}

Este texto procurou refletir sobre a ocupação do estado da região norte do Brasil Amapá/AP tendo como pano de fundo os imaginários e as crenças que serviram de atrativos e incentivos para o povoamento local, especificamente em sua área de fronteira. Buscou compreender como os imaginários sobre este pedaço de terra gerou e gera expectativas nos modos de ver e se posicionar os sujeitos sociais em plena expansão de trocas culturais. Explora e discute construções estereotipadas imbuídas em versões que qualificam e classificam os sujeitos acessando simbologias efetivadas por argumentos de progresso, civilidade e exotismo.

Segundo Edward Said (1995, p.37) "Tudo na história humana tem suas raízes na terra..." e nela que o sujeito constrói sua identificação. Então como se reconhecer na terra que não é sua, como lidar com sua própria cultura em espaço alheio? Como respeitar os limites que separam uma terra da outra, se esses limites já não são identificáveis? Deslocamento, diáspora, desterritorialização, migração. São os males que afligem e também o privilégio de que goza o homem globalizado. As palavras do autor intermediam muito bem as ideias propostas para este artigo que é de analisar o Amapá como a terra da promessa de onde mana riqueza e esperança. Nossa proposta foi de discutir a noção de fronteira como lugar que agrega em um único espaço diversas culturas e identidades.

Entendemos que a fronteira se converte em lugar de memória e assim ilustra as 
geografias e espacialidades onde as identidades encontram uma fixação simbólica que, por sua relevância, se transformam em lugares privilegiados do rememorar. Nessa direção, duas perspectivas do rememorar se revelam: a primeira delas inclui as recordações da origem- saudade; já a segunda localiza as experiências vividas no local habitado e promove a esperança. Para este estudo, os espaços rememorados remetem a ideia de protagonismo, numa terra inóspita, desvinculada da civilização, onde tudo estar por fazer.

Neste trabalho procuramos mostrar que os processos migratórios vivenciados na fronteira realça ainda uma relação de subalternidade entre as Comunas apresentadas, visto que o cidadão brasileiro na Guiana Francesa enfrenta muitas vezes a discriminação, a hostilidade aprisionando sua cultura em estereótipos.

A fronteira é um ponto de trânsito do presente, do passado, do futuro. Aborda a complexidade dos deslocamentos culturais onde o espaço e o tempo se cruzam produzindo diferenças, identidades, hibridizando culturas, nos dando uma sensação de desorientação, formando dessa maneira o que Homi Bhabha(1998) chamou de entrelugares. Lugar de transitoriedade e atração que pode ser bem sintetizado no contexto Amapá-Brasil e Guiana Francesa. Homi Bhabha em o Local da Cultura traz reflexões tênues sofre a concepção de fronteira ressaltando que:

Mais uma vez, é o desejo de reconhecimento, "de outro lugar e de outra coisa", que leva a experiência da história além da hipótese instrumental. Mais uma vez, é o espaço da intervenção que emerge nos interstícios culturais que introduz a invenção criativa dentro da existência. E, uma última vez, há um retorno à encenação da identidade como interação, a re-criação do eu no mundo da viagem, o re-estabelecimento da comunidade fronteiriça da migração. 0 desejo de reconhecimento da presença cultural como "atividade negadora" (...) afina-se com minha ruptura da barreira do tempo de um presente culturalmente conluiado (BHABHA, 1998, p. 29).

A fronteira aqui discutida é essa ruptura da barreira do tempo (BHABHA, 1998) indicando que o "aqui agora" é o que produziu a criação e recriação de espaços e, essa ocupação espacial foi, também, determinada por necessidades sociais criadas ao longo do tempo e fixada no espaço por meio do trabalho, das relações sociais e culturais como um conjunto indissociável de relações humana.

“(...) porque, por não reconhecer a contribuição dada à construção do real pela representação que os agentes têm do real, ele não pode compreender a real contribuição que a transformação coletiva de representação coletiva dá a transformação da realidade. Mas sem esquecer por isso que há uma economia do simbólico que é irredutível à economia (em sentido restrito) e que a luta simbólica tem fundamentos e efeitos econômicos (em sentido restrito) efectivamente reais". (BOURDIEU, 2002, p. 129).

M uito há ainda para se "explorar" na fronteira. Esta se arquiteta como indica Hall, 
em "rotas" ostentadas em sucessivos processos de negociação e cruzamentos entre mundos e fronteiras culturais. Enquanto limites territoriais e simbólicos, as fronteiras se tornam fluidas uma vez que por vezes mudam de posição, podem também ser alargadas ou ainda reduzidas. Na fronteira aqui analisada entre Amapá-Brasil e Guiana Francesa, verificamos que vem sendo cada vez mais ampliado, fato constatado pela construção da ponte binacional que desta forma continua a alimentar os imaginários e crenças construídos e desenhados na contramão da dimensão de progresso, civilidade, oportunidade de trabalho, serviços e qualidade de vida.

\section{REFERÊNCIAS}

ARRUDA. M arcos III - Daniel Ludwig e a Exploração da Amazônia. In: SILVEIRA Ênio. et al. Encontros com a Civilização Brasileira. Rio de Janeiro: Civilização Brasileira, 1979. CARRSACO. Juan Pablo. 0 tratado de Cooperação da Amazônia. In: In: SILVEIRA Ênio. et al. Encontros com a Civilização Brasileira. Rio de Janeiro: Civilização Brasileira, 1979.

BARREIRAS, Irlys A. F. "ritual e simbólico na politica. Cadernos CERU, série 2, n. 7, 1996. Pp 09-35.

BHABHA, Homi K. 0 local da cultura. Belo Horizonte: 3a ed. Ed. UFM G, 2005. BHABHA, Homi K. O Local da cultura. Belo Horizonte: Ed.UFM G,1998.

BOURDIEU, Pierre. 0 poder Simbólico. 16a edição, 2002

D'INCAO Maria Angela e SILVEIRSA, Maria Isabel (org.) A Amazônia e a Crise da Modernidade. Belém M useu Paraense Emilio Goeldi. 1994

FLORA, Susseking. Da sensação de não estar no todo. In: 0 Brasil não é longe daqui: o narrador, a viagem. São Paulo. Companhia das letras, 1990.

GIRARDET, Raoul. Mitos e Mitologias Politicas. São Paulo: Companhia das Letras, 1987.

HALL, Stuart. Da diáspora: Identidades e Mediações Culturais. Belo Horizonte: Editora UFM G, 2006.

ORTIZ, Renato. M undialização e cultura. São Paulo: brasiliense, 2000.

Revista:

SUPERTI. Eliane. A Fronteira Setentrional da Amazônia Brasileira no contexto das

Políticas de integração sul-americana. In: PRACS: Revista de Humanidades do Curso de Ciências Sociais da UNIFAP M acapá, n. 4, p. 01-16, dez. 2011.

SAID, Edward.Territórios sobrepostos, historias entrelaçadas. In: cultura e imperialismo. São Paulo: Companhia das Letras, 1995.p.33-98.

বhttp://g1.globo.com/fantastico/ noticia/2014/09/fantastico-revela-vida-de-garimpei ros-ilegais-na-guiana-francesa.html>

Artigo recebido em 22 de maio de 2015.

Aprovado em 18 de novembro de 2016. 